\title{
Assessment of some selected heavy metals in soot from the exhaust of heavy duty trucks and power generating plants in Nigeria by flame atomic absorption spectrophotometer
}

\author{
E. OKORIE ${ }^{*}$, C. OLORUNFEMI and H. SULE \\ Department of Science Laboratory Technology, Federal Polytechnic Idah P.M.B 1037 Idah, \\ Kogi State, Nigeria. \\ Corresponding author, E-mail: e.okorieslt@yahoo.com, Tel: +234-8-059430990
}

\begin{abstract}
Some selected heavy metals were determined in soot samples collected from heavy duty automobiles and diesel power generating plants in Idah Local Government Area of Kogi State, Nigeria. The results ind 0icated a high concentration of $\mathrm{Pb}, \mathrm{Cr}, \mathrm{Cu}$ and $\mathrm{Mn}$ in all the samples. Cadmium was observed in six of the samples and was not detected in samples MB3 and G1. Of all the parameters analysed, Pb had the highest concentrations of $12.1352 \pm 5.007 \mathrm{ppm}$ in sample T 2, followed by MB 3 at $5.1573 \pm 0.604 \mathrm{ppm}$. However the average discharge of $\mathrm{Pb}$ to the environment was $4.4511 \mathrm{ppm}$. Average discharge of $\mathrm{Cd}$ in the soot samples was $0.3964 \mathrm{ppm}$, while that of $\mathrm{Cr}, \mathrm{Cu}$ and $\mathrm{Mn}$ were $0.4898 \mathrm{ppm}, 0.8612 \mathrm{ppm}$ and $1.8851 \mathrm{ppm}$ respectively. These values are far above the World Health Organization maximum acceptable limits for air and water emissions and are therefore high source of pollution with its attendant health risks as previously reported in literature.

(C) 2009 International Formulae Group. All rights reserved.
\end{abstract}

Keywords: Soot, FAAS, Pollution, Heavy metals.

\section{INTRODUCTION}

Air quality has improved in Nigeria since the inception of the act curtailing gas flaring and other gaseous pollutants, many Nigerians, however, still live in areas with unsafe levels of fine particle pollution that exceeds national and international health standards (GFB, 2009). Power plants, heavy duty trucks and automobiles are the nation's largest industrial and domestic sources of air pollution (Querot et al., 2001). These emissions undoubtedly fuel global warming and cause other serious public health and environmental problems.

Soot in the oil is a natural occurrence for diesel engines, however, too much soot causes the lubricant to become too viscous and thus not lubricate well (Desjardins and Seifert, 1994). Research into soot suggests that the size distribution during normal operation varies, but averages about 0.078 micron (Donnet et al., 1997; Mitsuhiro et al., 1996; Timothy et al., 1998). Normally, soot generated during combustion exits via the engine's exhaust system. Several epidemiological studies have demonstrated a direct association between heavy metals found in soot and people's health. Exposure to increased levels of $\mathrm{Pb}, \mathrm{Cd}, \mathrm{Cr}, \mathrm{Cu}$ and $\mathrm{Mn}$ shows a high correlation with increase in brain and kidney damage, holes and ulcers in the nasal septum, impaired motor function, brain damage and cardiovascular disease (Schmitt, 1999; Eck and Wilson, 1989; Dockery et al., 
1993; Hoek et al., 1997; Harrison and Yin, 2000; Baker et al., 1979). Studies have indicated more consistent effects for high concentrations of the fine and inhalable particles with health effects than for other atmospheric pollutants (Schwartz et al., 1996, Samet et al., 2000).

Several studies on heavy metal addition in lubricating oil and soot deposition indicated enhanced engine wear (Shrawan et al., 2006; Kaneta et al., 2006) and decrease the sooting limit due to the reduction in fuel concentration and temperature (Du et al., 1995; Docekal et al., 1992; Carlos et al., 2007). The presence of these heavy metals may be ascribed to fuel additives as previously reported (DieselNet, 2000; Mayer, 1998; Mayer et al., 1999; HEI, 1998). Reports indicating the size, morphology and elemental composition of soot particles have been carried out (Hinshaw et al., 1992; Meij, 2000).

Although the intention of these heavy metal uses is beneficial, such as to reduce emissions of concern, metals have the potential of causing deleterious effects themselves or of causing other changes in emissions that may increase toxicity such as changing the particle size distribution (Hinshaw et al., 1992). Therefore, the aim of this research is to create awareness on the potential health effects of these metals in the environment and to serve as guide of new metal-containing additives or engine developments before their widespread adoption. Because it is difficult to predict the toxicity of one metal based on effects of another, and because the chemical form of the metal may affect its toxicity, it is critical to conduct research on new metal additives before their widespread use.

\section{MATERIALS AND METHODS Chemicals and reagents}

All the chemicals and reagents used in this study were of analytical grade. The deionized water used was further purified by distillation using a water distiller. $\mathrm{HCl}$, nitric acid, 4-methyl-2-pentanone and methyl isobutyl ketone (MIBK) were purchased from Zigma-Aldrich (Germany).

\section{Instrumentation}

The FAAS instrument used was Pye Unicam 969 Flame Atomic Absorption Spectrophotometer (Cambridge, England). A direct aspiration was employed and an airacetylene flame was used at a flame speed of $145 \mathrm{~cm} / \mathrm{s}$ and a temperature of $1900-2100{ }^{\circ} \mathrm{C}$ for $\mathrm{Pb}, \mathrm{Cr}, \mathrm{Cu}$ and $\mathrm{Mn}$. A nitrous oxideacetylene flame at a flame speed of $160 \mathrm{~cm} / \mathrm{s}$ and a temperature of $2650-2750{ }^{\circ} \mathrm{C}$ was used for $\mathrm{Cd}$ determination.

\section{Sampling/sample preparation}

Soot samples were collected from the exhaust of heavy duty trucks (Fiat and Mercedes Benz 911) and diesel powered electric generators. All samples were collected at Idah metropolis Kogi State, Nigeria, and stored in plastic containers to eliminate adsorption. The samples were subsequently dried in an oven at a temperature of $105{ }^{\circ} \mathrm{C}$ for 1 hour to eliminate moisture. Sampling period was $15^{\text {th }}$ June to $20^{\text {th }}$ June 2008 .

\section{Analysis (digestion)}

A $20 \mathrm{~mL}$ of concentrated $\mathrm{HCl}$ was added to $1 \mathrm{~g}$ of each of the soot samples from heavy duty truck and heated on a Gallenkamp heating mantle until dissolution was complete. This was then filtered into a $100 \mathrm{~mL}$ volumetric flask and the filtrate made to the mark with distilled water. Due to its oily nature, MIBK and 4-methyl-2-pentanone in the ratio of $1: 1$ was added to $1 \mathrm{~g}$ each of the two soot samples from two different diesel power generators and then subjected to heating until dissolution was achieved. The filtered samples were transferred to a $100 \mathrm{~mL}$ flat bottomed flask and made to the mark with distilled water. Direct aspiration of the samples in a nebulization burner using an airacetylene flame and a nitrous oxide-acetylene flame was carried out. However, stock standards of $\mathrm{Pb}, \mathrm{Cd}, \mathrm{Cr}, \mathrm{Cu}$ and $\mathrm{Mn}$ were prepared using analytical reagent grades from 
Zigma-Aldrich, Germany. The samples were subjected to six determinations and the results were recorded.

\section{RESULTS AND DISCUSSION}

The results of the determination of $\mathrm{Pb}$, $\mathrm{Cd}, \mathrm{Cr}, \mathrm{Cu}$ and $\mathrm{Mn}$ in soot samples from heavy duty truck and diesel power generators in Idah, Nigeria are summarized in Table 2. From the results, it can be seen that variations exists in the concentrations of lead recorded in the soot samples. T 2 showed a significant concentration of lead in its soot of $12.1352 \pm 5.007 \mathrm{ppm}$. This high value may be ascribed to variations in the concentration of lead-based metal additives that was used as an anti-knock and may also be due to aging of the truck (Docekal et al., 1992). The power generator, G1, recorded the lowest value of lead at $1.4880 \pm 0.505$. This low value may be due to low level of lead additives in the diesel fuel and the absence of wearable lead-based alloys in the component parts of the engine (bearings) (DieselNet, 2000; Mayer, 1998). In comparison to acceptable standard limits, these results are far above the recommended emission standards for both air and water and are therefore objectionable to human and the environment (PCGID, 2003; WHO, 2000; SUMITOMO, 2007).

Table 1: Recommended standards for air emissions (PCGID, 2003).

\begin{tabular}{lll}
\hline Substance & $\begin{array}{l}\text { Trade, industry, process, } \\
\text { fuel burning equipment } \\
\text { or industrial plant }\end{array}$ & Emission limits \\
\hline Lead and its compound & Any trade, industry or process & $5 \mathrm{mg} / \mathrm{Nm}^{3}$ expressed as lead \\
Cadmium and its compounds & Any trade, industry or process & $3 \mathrm{mg} / \mathrm{Nm}^{3}$ expressed as cadmium \\
Chromium and its compound & Any trade, industry or process & $10 \mathrm{mg} / \mathrm{Nm}^{3}$ expressed as chromium \\
Copper and its compound & Any trade, industry or process & $5 \mathrm{mg} / \mathrm{Nm}^{\mathbf{3}}$ expressed as copper \\
Manganese and its compounds & Any trade, industry or process & 0.05 expressed as manganese \\
\hline
\end{tabular}

Table 2: Results of $\mathrm{Pb}, \mathrm{Cd}, \mathrm{Cr}, \mathrm{Cu}$ and $\mathrm{Mn}$ determination in soot samples found in Idah.

\begin{tabular}{llccccc}
\hline \multirow{2}{*}{$\begin{array}{l}\text { Sample } \\
\text { code }\end{array}$} & Samples & \multicolumn{5}{c}{ Concentration in ppm } \\
\cline { 3 - 7 } & & Pb & Cd & Cr & Cu & Mn \\
\hline T 1 & Trailer 1 & $2.2043 \pm 0.202$ & $0.5122 \pm 0.09$ & $0.7549 \pm 0.08$ & $1.5728 \pm 0.015$ & $1.5003 \pm 0.013$ \\
T 2 & Trailer 2 & $12.1352 \pm 5.007$ & $0.5829 \pm 0.011$ & $0.6157 \pm 0.051$ & $0.5368 \pm 0.018$ & $0.8521 \pm 0.029$ \\
T 3 & Trailer 3 & $3.7543 \pm 0.301$ & $0.6500 \pm 0.18$ & $0.3376 \pm 0.044$ & $1.0489 \pm 0.088$ & $0.9906 \pm 0.046$ \\
MB 1 & Merc 911, 1 & $4.2960 \pm 0.517$ & $0.6986 \pm 0.20$ & $0.1750 \pm 0.037$ & $0.6531 \pm 0.032$ & $0.5845 \pm 0.077$ \\
MB 2 & Merc 911, 2 & $4.0530 \pm 0.311$ & $0.7200 \pm 0.41$ & $0.6596 \pm 0.023$ & $0.7965 \pm 0.059$ & $8.8933 \pm 2.008$ \\
MB 3 & Merc 911, 3 & $5.1573 \pm 0.604$ & $\mathrm{ND}$ & $0.2989 \pm 0.072$ & $1.4093 \pm 0.089$ & $1.7560 \pm 0.083$ \\
G 1 & Generator 1 & $1.4880 \pm 0.505$ & $\mathrm{ND}$ & $0.6882 \pm 0.066$ & $0.5336 \pm 0.008$ & $0.4110 \pm 0.037$ \\
G 2 & Generator 2 & $2.3603 \pm 0.022$ & $0.0072 \pm 0.26$ & $0.3888 \pm 0.009$ & $0.3386 \pm 0.094$ & $0.0930 \pm 0.008$ \\
Maximum acceptable air & $5 \mathrm{mg} / \mathrm{Nm}^{3}$ & $3 \mathrm{mg} / \mathrm{Nm}^{3}$ & $10 \mathrm{mg} / \mathrm{Nm}^{3}$ & $5 \mathrm{mg} / \mathrm{Nm}^{3}$ & $0.05 \mathrm{mg} / \mathrm{Nm}^{3}$ \\
limits & & & & & \\
\hline
\end{tabular}

ND = Not detected. 


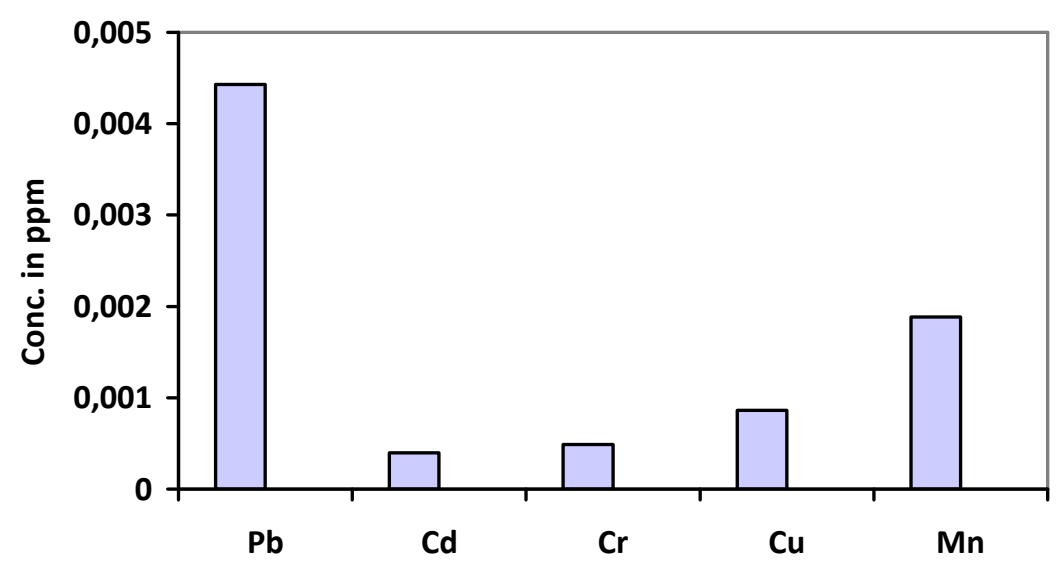

Figure 1: Bar Chart showing average distributions of $\mathrm{Pb}, \mathrm{Cd}, \mathrm{Cr}, \mathrm{Cu}$ and $\mathrm{Mn}$ in a $1.0 \mathrm{~g}$ soot sample found in Idah, Nigeria.

Possible consequences in human include decreased function of the nervous system, increase in blood pressure, reproductive dysfunction, and brain and kidney damage in adults and especially in children (Hoek et al., 1997; Baker et al., 1979; Harrison and Yin, 2000).

The observed concentrations of cadmium in all the samples are all below 1.0 ppm. These concentrations are far above the standards for air and therefore not within acceptable limits. However, this element is not biodegradable and over exposure will ultimately lead to bioaccumulation in humans and the environment. After long term exposure, the kidneys may contain more than half of the body burden of cadmium (Irwin et al., 1997; Borjesson et al., 2000; Jamp et al., 1998; Moon et al., 1999).

Chromium concentrations were far above the acceptable limits as compared to standards. However, these objections may be attributed to wears in the engine and additives in the oil as previously reported (DieselNet, 2000; Mayer, 1998; Mayer et al., 1999). If present in the environment, chromium may be responsible for lung cancer, nose bleeds holes and ulcers in the nasal septum (Meij, 1994).
The presence of chromium can change the composition of an ecosystem, altering species diversity (USEPA, 1996).

Copper concentrations in the soot are all below the maximum acceptable limits for air and water emissions and are therefore not harmful. These low concentrations may be ascribed to the activities of copper additives which decreases particulate matter emissions, lower the soot combustion temperature and facilitate filter generation as recorded in previous research (DieselNet, 2000; Mayer et al., 1999). However, long term exposure may lead to increase in its concentration in the soil and may result to bioaccumulation in plants (Mayer, 1998).

Manganese concentrations as recorded from the soot analysis are generally low except for samples from T 1, MB 2 and MB 3 whose values are above $1 \mathrm{ppm}$ and are $1.5003 \pm 0.013 \mathrm{ppm}, 8.8933 \pm 2.008 \mathrm{ppm}$ and $1.7560 \pm 0.083 \mathrm{ppm}$ respectively. However, these values are all objectionable to the environment and in humans (Meij, 2000; WHO, 2000). Therefore, manganese-based fuel additives may be responsible for this increase. Such concentrations if subjected to long term exposure may result in manganism, 
a neurological condition similar to Parkinson's disease (HEI, 2001).

\section{Conclusion}

Most of us are aware of the health effects of combustion by-products from major outdoor sources, such as cars and power plants, and even from obvious indoor sources such as stoves. Soot from the study can sometimes contain toxic heavy metals such as lead, Cadmium, chromium, copper and manganese which are released to the environment. This study has however highlighted the various concentrations of these heavy metals in the environment. Some of these metals such as lead indicated an objectionable value of $12.1352+5.007 \mathrm{ppm}$. Copper, manganese, cadmium and chromium whose concentrations are below the acceptable maximum limit for air quality may bioaccumulate over a long exposure in plants and humans. These objectionable releases however increase the presence of these metals in air and water bodies. Therefore, the attendant health effects may adversely affect persons living around the study area. These concentrations may be curtailed by close monitoring of metal-based fuel additives which has been found to contribute significantly to these increases. Proper monitoring of these metal additives to conform to international standard (SUMIMOTO, 2007) is necessary to avert the inherent pollution of the environment by these heavy metals.

\section{ACKNOWLEDGEMENTS}

The National Metallurgical Development center, Jos, Nigeria is highly acknowledged for making their facilities available for this research. We are highly indebted to Mr. C.I.C Nwankwo of the institute for his advice and encouragement. We also appreciate the kind assistance of Mallam Haliru Labaran of the institute for carrying out some of the elemental determinations using the institutes Flame Atomic Absorption Spectrophotometer.

\section{REFERENCES}

Baker Jr EL, Peterson WA, Holtz JL, Coleman C, Landrigan PJ. 1979. Subacute cadmium in toxication in jewelry workers; an evaluation of diagnostic procedures. Arch. Environ. Health, 34: 173-177.

Borjesson J, Gerhardsson L, Schutz A, Perfekt R, Mattsson S, Skerfving S. 2000. Kidney cadmium as compared to other markers of cadmium exposure in workers at a secondary metal smelter. Am. J. Ind. Med., 39: 19-28.

Carlos EC, Wagner FP, Rangel S, Marcio LNR, Percio AMF, Ricardo QA. 2007. Voltammetric determination of copper and lead in gasoline using sample preparation as microemulsions. Anal. Sci. 23: 1065-1069.

Desjardins J, Seifert W. 1994. Soot and your diesel engine. Lubrication system, proceedings of the Joint oil Analysis Program (JOAP) Conference.

DieselNet Technology Guide. 2000. 02b, Diesel Filter Systems, Traps with Fuel Additives. DieselNet.

Docekal B, Krivan V, Pelz N. 1992. Trace and minor element characterization of diesel soot. Fresenius' J. Anal. Chem., 343(12): 873-879.

Dockery D, Pope C, Xu X, Spengler J, Ware J, Fay M, Ferris B, Speizer F. 1993. An association between air pollution and mortality in six U.S. cities. N. Engl. J. Med., 329: 1753-1759.

Donnet J, Peng C, Wang T. 1997. Scanning tunnelling microscopy study for lubricating oil soots. Carbon, 35(6): 853-854.

Du DX, Axelbaum RL, Law CK. 1995. Soot formation in strained diffusion flames with gaseous additives. Combustion and Flame, 102(1-2): 11-20. 
Eck P, Wilson L. 1989. Toxic Metals in Human and Disease. Eck Institute of Applied Nutrition and Bioenergetics, Ltd A2 P xiv.

FGN. 2009. Gas Flaring and Prohibition Bill. Federal Government of Nigeria. http://allafrica.com/stories/20090703011 9.html

Harrison R, Yin. 2000. Particulate matter in the atmosphere: which particle properties are important for its effects on health? J. Sci. Total Environ., 249: 85101.

HEI Attachment A. 1998, Summary of a Workshop on Metal-Based Fuel Additives and New Technologies. The Health Effects Institute. http://www.healtheffects.org.rfa.RFA 98-attachment A.htm.

HEI Communication 9. 2001. Evaluation of Human Health Risk from Cerium Added to Diesel Fuel. The Health Effects Institute.

Hinshaw G, Gilford P, Kinsey J, Sack., Huffman G, Lin P. 1992. Formation and characterization of soot deposits from Non-Optimum Combustion of No. 6 fuel oil with chlorinated organic compounds in an industrial boiler. Combustion Science and Technology, 85(1-6): 243258.

Hoek G, Schwartz J, Groot B, Eilers P. 1997. Effects of ambient particulate matter and ozone on daily mortality in Rotterdam, The Netherlands. Arch. Environ. Health, 52: 455-463.

Irwin RJ, VanMouwerik M, Stevens L, Seese MD, Basham W. 1997. Environmental Contaminants Encyclopaedia. National Park Service, Water Resources Division, Fort Collins: Colorado.

Jamp L, Alfven T, Persson B, Toss G, Elinder CG. 1998a. Cadmium may be a risk factor with osteoporosis. Oсcup. Environ. Med., 55: 435-439.
Kaneta M, Irie T, Nishikawa H, Matsuda K. 2006. Effects of soot on wear in elastohydrodynamic lubrication contacts. Proceedings of the $1 \mathrm{MECH}$ E Part J. J. Engr. Tribology, 220(3): 307-317.

Mayer A. 1998. Available Particulate trap systems for diesel engines, VERT: Suva, AUVA,TBG, BUWAL. Report TTM W04/4/98, version Nr. 5.

Mayer A, Matter U, Czerwinski J, Heeb N. 1999. Effectiveness of particulate traps on construction site engines: VERT Final Measurements. DieselNet Technical Report.

Meij R. 1994. Trace elements behavior in coal-fired power plants. Fuel, 3: 199.

Meij R. 2000. Composition and particle size of and exposure to coal fly ash. $J$. Aerosol Sci., 31(1): S676.

Mitsuhiro J, Daisuke S, Toshikau K, Hiroshi Y. 1996. Observation of sooting behavior in an emulsion droplet flame by planar laser light scattering in microgravity. Symposium (International) on Combustion, 26(1): 1251-1258.

Moon CS, Zhang ZW, Shimbo S, Watanabe T, Lee CW, Lee BK. 1999. Evaluation of urinary cadmium and lead as markers of background exposure of middle-aged women in Korea: dietary intake as an influential factor. Toxicol. Lett., 108: 173-178.

Pollution Control Guidelines for Industrial Development, 2003. Recommended Standards for Air Emissions, Pp 13-15.

Querot X, Alastuey A, Rodriguez S, Plana F, Mantilla E, Ruiz C. 2001. Monitoring of PM 10 and PM 2.5 around primary particulate anthropogenic emission sources. Atmo. Environ., 35: 845-858.

Samet J, Dominici F, Curriero F, Coursac I, Zeger S. 2000. Fine particulate air pollution and mortality in 20 U.S. cities, 1987-1994. N. Engl. J. Med., 34: 17421749. 
Schwartz J, Dockery D, Neas L. 1996. Is daily mortality associated specifically with fine particles? J. Air Waste Manage. Assoc., 46: 2-14.

Scmitt CJ. 1999. Environmental Contaminants. In Status and Trends of the Nations Biological Resources (Vol. 1), Mac MJ, Opler PA, Puckett CE, Haecker, Doran PD (eds). U.S. Department of the Interior, U.S. Geological Biological Resources division, Environmental and Contaminants Research Center Survey: Reston, VA; 131-166.

Shrawan KS, Avinash KA, Mukesh S. 2006. Experimental investigations of heavy metal addition in lubricating oil and soot deposition in an EGR operated engine. Appl. Thermal Engineering, 26(2-3): 259-266.
SUMITOMO BAKELITE. 2007. SiteSpecific Environmental Impact Data Overseas Business Sites. Environmental and social report pp 31-32.

Timothy LD, Froelich D, Sarofin AF, Beer JM. 1998. Soot formation and burnout during the combustion of dispersed pulverized coal particles. Symposium (International) on Combustion, 21(1): 1141-1148.

US EPA. 1996. Study of Hazardous Air Pollutant Emissions from Electric Utility Steam Generating Units - Final Report to Congress. http://www.epa.gov/ $\mathrm{ttn} / \mathrm{caaa} / \mathrm{ts} /$ reports/eurtc1.pdf.

WHO. 2000. Guidelines on Drinking Water and Air Quality. World Health Organization: Geneva, Switzerland. 